\title{
Smoking, social traps, and futuristics
}

\author{
ROBERT J. WEBER, MARILYN MALLUE, and JOE CONNER \\ Oklahoma State University, Stillwater, Oklahoma 74074
}

\begin{abstract}
Smoking behavior served as a convenient example of a social trap. A social trap consists of two factors: costs and benefits, with different time courses. A potential trap exists when initially benefits are greater than costs, but over time or over exposures costs overtake benefits. Three scaling studies were conducted using a modified Delphi forecasting method to examine perceived smoking abstention rates over periods from $1 \mathrm{~min}$ to 30 years as a function of various incentive conditions (ranging from death to a dollar) and varying probabilities of obtaining the incentives. People made consistent judgments: They trade off probable consequences and time. For example, if death is sufficiently improbable or removed in time, it is judged to have less effect on stopping present smoking behavior than if it is either highly probable or closer in time to the smoking behavior. Smoking is a Faustian act: Future costs are traded for present benefits.
\end{abstract}

Platt (1973) has defined a social trap as a situation in which the immediate incentives for a behavior are positive, while the long-term incentives are negative. Solomon and Corbit (1973) have theorized in a similr vein on the reasons for the development of apparently addictive behaviors such as smoking. This class of theories can be thought of as positing two underlying factors, costs and benefits. 1 Benefits begin at a positive level on some decision variable, and with the passage of time or increased use, they begin to fade. In contrast, costs begin at a zero or low level, and with the passage of time or increased use, they begin to increase in strength. If the participant attends to or tracks primarily the benefits, he is likely to become thoroughly trapped by the behavior. This could arise by having a lower, more liberal, decision criterion or cutoff for benefits than for costs.

There is a need for very long-term knowledge of smoking behaviors and attitudes. In particular, how do people perceive the future of smokers and smoking over periods as long as 30 years? In the absence of readily available real time data, it is possible to use some of the methods employed by futurists (Gordon, 1972) in their forecasts. One possibility is a variation on the Delphi method. With this method, experts are independently polled on, for example, when they think a certain breakthrough in technology will occur. Other steps in the method then follow in an attempt to gain a better estimate. The part of the method described, however, is a simple psychological scaling technique, numerical estimation. The use of expert opinion is not essential to the method if the phenomenon in question is familiar to everyone, as smoking may be. But smokers and nonsmokers might differ systematically in their estimates because of their familiarity with smoking.

This study was supported by a grant from the Research Foundation, Oklahoma State University, to the first author. It was completed while the first author was a visiting professor at the University of Oregon. Requests for reprints should be sent to Robert J. Weber, Psychology Department, Oklahoma State University, Stillwater, Oklahoma $\mathbf{7 4 0 7 4 .}$
In this context, it is of interest to examine people's long-term perceptions of smoking and smokers under a series of hypothetical delays between smoking behavior and ultimate consequences. The delay intervals studied range from $1 \mathrm{~min}$ to 30 years. Obviously, we are not necessarily studying an empirical reality here in the sense that the scaling results would mirror how people actually behave. But at the very least, it is of interest to know something about people's perceptions of smokers. It may turn out to be the case that those perceptions do, in fact, have a correspondence to behavioral reality. Thus, people have considerable ability for making frequency judgments of at least some behaviors (Tversky \& Kahneman, 1973). But if perceptions do not mirror reality, they are still of interest because people's behaviors in regard to acceptance/nonacceptance of smoking are likely to be guided by their perceptions of smoking and smokers.

In Study I, we examine the relation between smoking and ensuing death at various intervals. In Study II, we look at likelihood of stopping smoking as a function of the probability of being paid for stopping. And in Study III, the likelihood of stopping is examined as a function of amount of payment for stopping for various intervals of time.

\section{STUDY I: DEATH AS A CONSEQUENCE OF CONTINUED SMOKING}

Smoking may reasonably be labeled as an addictive behavior in the sense that it is a behavior that one wants to stop but cannot, even though repeated attempts are made to stop (Brecher, 1972). The tenacity of the behavior is underscored by referring to Burgher's disease, an affliction that results in decreased blood supply to the extremities, particularly the legs (Brecher, 1972). The disease is sharply aggravated by smoking. Evidently, nicotine decreases the diameter of capillaries, and, with diminished blood supply, gangrene may set in, with amputation resulting. According to Brecher, it is not 


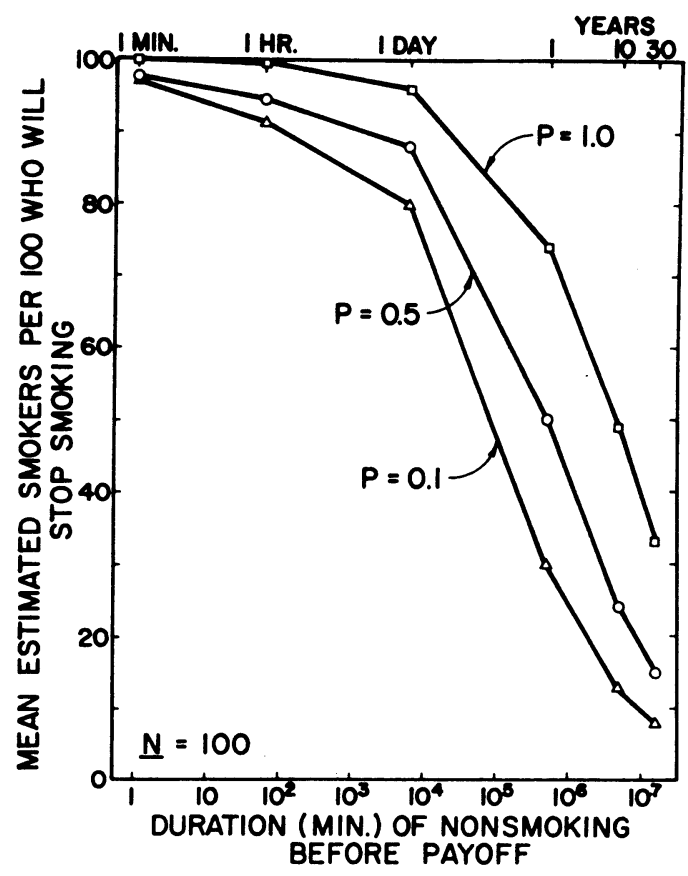

Figure 1. Mean estimated smokers per 100 who will stop smoking as a function of delay between smoking and death, and probability of death.

uncommon for a patient who has had several amputations to be found smoking in bed the day after his latest amputation! This is in spite of the fact that by stopping smoking, the circulation problem would become stabilized and manageable without either gangrene or a corresponding amputation. In view of the smoker's remarkable need, would he be willing to risk even his life for another cigarette? Would this risk be differentially perceived by smokers and nonsmokers?

\section{Method \\ A total of 104 people from a beginning course in experimental psychology with no known previous work in this area, were provided with a questionnaire during class. The questionnaire depicted a hypothetical situation in which tobacco plants underwent a mutation that resulted in their becoming potentially lethal for the smoker. As a result of smoking one more cigarette, death might occur with varying probabilities and with varying time lags. There were two forms of the questionnaire. One form varied the probability of death in the order $.1, .5$, and 1.0 , while the other form reversed this order. The two forms were randomly assigned to seats. Subjects indicated on the form if they were smokers or not. The subjects were to judge for each time lag and death probability the number of smokers out of a typical sample of 100 who they thought would stop smoking because of the potentially lethal character of tobacco. This number, from 0 to 100 , was the dependent variable.}

\section{Results and Discussion}

Figure 1 reveals a regular pattern of a decreasing number of smokers willing to stop as the delay interval from smoking to death is increased and as the probability of death varied. The upper $X$ axis is in the naturally occurring time units used on the questionnaire. For continuity, the lower $\mathrm{X}$ axis is in the equivalent log minutes. If the delay interval is beyond a day, many subjects judge that a confirmed smoker would not be able to abstain successfully. Whether this is a realistic prediction of actual smokers' behaviors, it remains as an intriguing finding on how people perceive smokers. Moreover, it is not too discrepant from the observations on Burgher's syndrome.

The probability of death is also consistently reflected in subjects' perceptions of smokers. Give the smoker increasingly better odds in escaping death, and he will be more likely to smoke that next cigarette.

Originally, it was intended to compare smokers and nonsmokers. However, the total number of smokers was less than $20 \%$ and scattered unevenly across the two survey forms. Hence, no such comparison was made, nor was it made in the other studies in the series for the same reasons.

Examination of the two forms did not reveal any consistent differences, possibly because subjects were instructed to work back and forth among their answers in order to make them consistent.

\section{STUDY II: \$1 MILLION AS A PAYOFF FOR ABSTENTION}

A behavioral method of deterring undesirable behavior is to offer payment contingent on not engaging in the behavior. This is a DRO schedule if we do not specify what behaviors other than smoking may be engaged in for payoff. The rationale of the DRO method is to ensure that the benefits for engaging in other behaviors are greater than for the net benefits of the behavior in question, namely, smoking. The relative benefits are presumably compared on some decision axis. A reasonable question would be to ask how the probability of receiving a large sum of money might influence or induce people not to smoke. Another question would ask how delay of payment would influence people in not smoking. Again, the immediate concern is with people's perception of these influences.

\section{Method}

The method employed was essentially identical to that of the first experiment, except for the questions differing in content. The general form of the question asked how many smokers out of 100 would stop smoking for a given time interval and a given probability of receiving $\$ 1$ million for successful abstention until the end of the interval. There were again two different forms to counterbalance the order of delay and probability conditions. There were 100 subjects from the same class, but in a different semester.

\section{Results and Discussion}

A highly regular pattern of results is indicated in Figure 2. The longer the delay or abstention interval until payment of the $\$ 1$ million, the fewer the smokers per hundred who would be expected to abstain successfully. With the probability variable, the higher the probability of payoff, the greater the number of smokers who would be expected to abstain successfully. 


\section{STUDY III: VARYING THE PAYOFF FOR ABSTENTION}

The effectiveness of a DRO schedule would be expected to relate to magnitude of reinforcement, in particular to the amount of money in the payoff for abstention. In this study, the payoff is varied from $\$ 1$ million to $\$ 1$. Probability of payoff is not varied, being held at a constant 1.0 .

\section{Method}

The present procedures were essentially the same as for the prior studies. The order of questions for different payoffs always was from $\$ 1$ to $\$ 1$ million.

\section{Results and Discussion}

Figure 3 illustrates that the amount of payoff is an effective variable in the perception of smokers' behaviors. The lower curve indicates an obvious truism: $\$ 1$ will not buy much anymore. The holding power of $\$ 100$ is still considerable. But in all cases, there is a steady drop-off over time, indicating that people perceive smoking as a very pernicious behavior.

What do people perceive as important or potentially important variables affecting the behavior of smokers? First, consequences are important. If the consequences of smoking or nonsmoking range from death to a dollar, there are varying degrees of abstention. Second, as the delay or abstention interval increases between smoking and its consequences, there is progressively less effect on abstention. Smokers will go back to smoking. They are willing to trade off consequences and time with one another. "Everyone dies sometime and my own death from smoking does not diminish my present life, if that death is sufficiently far in the future." Third, an element

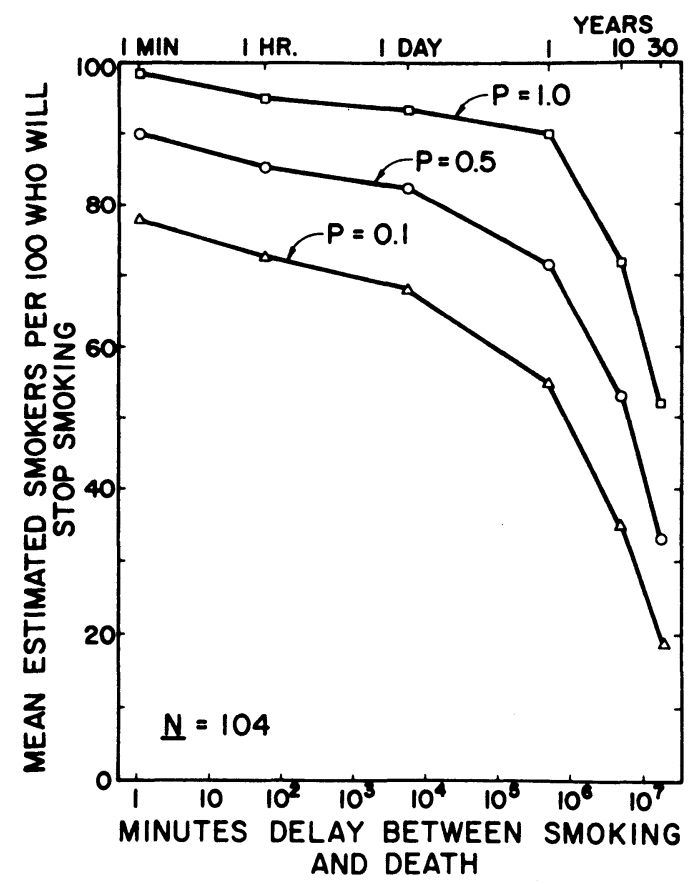

Figure 2. Mean estimated smokers per 100 who will stop smoking as a function of delay duration and probability of receiving \$1 million at the end of the delay.

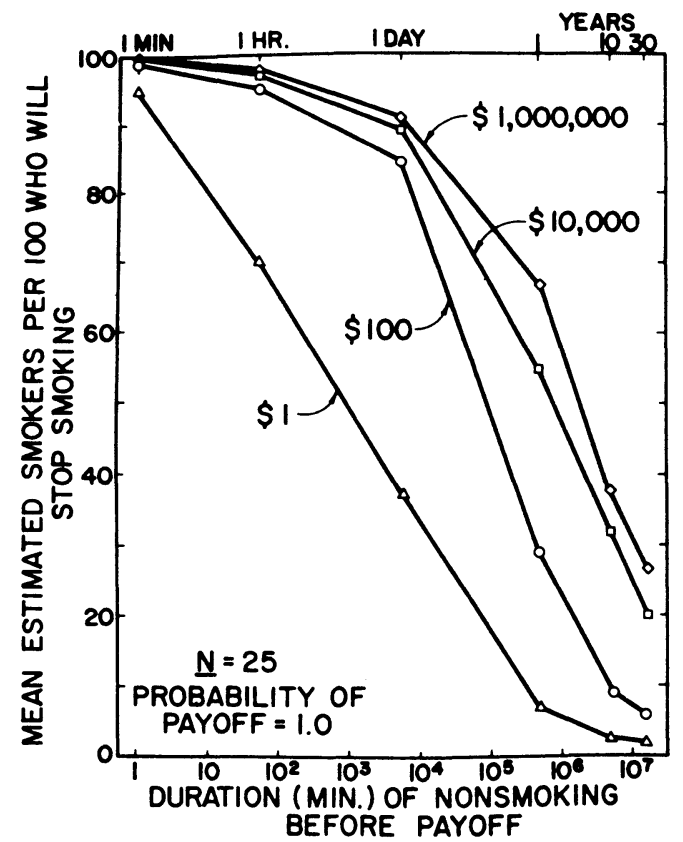

Figure 3. Mean estimated smokers per 100 who will stop smoking as a function of delay duration and payoff value at the end of the delay.

of risk or gambling is perceived to be important in the smokers' behavior. As long as the odds against death are not hopeless, people think some smokers are likely to persist.

How realistic are these perceptions of smokers? Would real smokers behave in the ways indicated? It is not possible to answer in detail, but there is no doubting the persistence of smoking over long periods of time for many smokers who want to quit, decide to quit, and repeatedly try to quit but cannot do so. While a long-range validation of the present results is probably not possible, short-range studies over a several-day period might answer part of the problem.

The cost-benefit analysis and the variables investigated suggest that smoking is a Faustian act: Present benefits are traded for future costs.

\section{REFERENCES}

Brecher, E. M. Licit and Illicit drugs. New York: Consumers Union, 1972.

Gordon, T. Current methods of futures research. In A. Toffler (Ed.) The futurists. New York: Random House, 1972.

Platt, J. R. Social traps. American Psychologist, 1973, 28, 641-651.

Posner, M., \& Snyder, C. Attention and cognitive control. In R. Solso (Ed.), Information processing and cognition: The Loyala Symposium. Potomac, Maryland: Lawrence Erlbaum Associates, in press.

Solomon, R., \& Corbit, J. An opponent process theory of motivation: II. Cigarette addiction. Journal of Abnormal Psychology, 1973, 81, 158-171.

Tversky, A., \& Kahneman, D. Availability: A heuristic for judging frequency and probability. Cognitive Psychology, 1973, 5, 207-232.

\section{NOTE}

1. The notion of costs and benefits has previously been employed by Posner and Snyder (in press), but in a very different context.

(Received for publication March 9, 1975.) 